Marquette University

e-Publications@Marquette

Biological Sciences Faculty Research and

Publications

Biological Sciences, Department of

$11-1998$

\title{
Force-velocity-power and Force-pCa Relationships of Human Soleus Fibers After 17 Days of Bed Rest
}

\author{
Jeffrey J. Widrick \\ Marquette University \\ Kris M. Norenberg \\ Marquette University \\ C. A. Blaser \\ Marquette University \\ M. Karhanek \\ Marquette University \\ Jennifer J. Sherwood \\ Marquette University
}

See next page for additional authors

Follow this and additional works at: https://epublications.marquette.edu/bio_fac

Part of the Biology Commons

\section{Recommended Citation}

Widrick, Jeffrey J.; Norenberg, Kris M.; Blaser, C. A.; Karhanek, M.; Sherwood, Jennifer J.; Trappe, Scott W.; Trappe, Todd A.; Costill, David L.; and Fitts, Robert H., "Force-velocity-power and Force-pCa Relationships of Human Soleus Fibers After 17 Days of Bed Rest" (1998). Biological Sciences Faculty Research and Publications. 448.

https://epublications.marquette.edu/bio_fac/448 


\section{Authors}

Jeffrey J. Widrick, Kris M. Norenberg, C. A. Blaser, M. Karhanek, Jennifer J. Sherwood, Scott W. Trappe, Todd A. Trappe, David L. Costill, and Robert H. Fitts 
Marquette University

e-Publications@Marquette

\section{Department of Biology Faculty Research and Publications/College of Health Sciences}

This paper is NOT THE PUBLISHED VERSION; but the author's final, peer-reviewed manuscript. The published version may be accessed by following the link in the citation below.

Journal of Applied Physiology, Vol. 85, No. 5 (November, 1998): 1949-1956. DOI. This article is (C) American Physiological Society and permission has been granted for this version to appear in $\underline{\mathrm{e}}-$ Publications@Marquette. American Physiological Society does not grant permission for this article to be further copied/distributed or hosted elsewhere without the express permission from American Physiological Society.

\section{Force-velocity-power and force-pCa relationships of human soleus fibers after 17 days of bed rest}

\section{J. J. Widrick}

Department of Biology, Marquette University, Milwaukee, Wisconsin K. M. Norenberg Department of Biology, Marquette University, Milwaukee, Wisconsin J. G. Romatowski

Department of Biology, Marquette University, Milwaukee, Wisconsin C. A. Blaser

Department of Biology, Marquette University, Milwaukee, Wisconsin M. Karhanek

Department of Biology, Marquette University, Milwaukee, Wisconsin J. Sherwood

Department of Biology, Marquette University, Milwaukee, Wisconsin 


\title{
S. W. Trappe
}

Human Performance Laboratory, Ball State University, Munice, Indiana

\section{T. A. Trappe}

Human Performance Laboratory, Ball State University, Munice, Indiana

\section{L. Costill}

Human Performance laborator, Ball State University, Munice, Indiana

\section{R. H. Fitts}

Department of Biology, Marquette University, Milwaukee, Wisconsin

\begin{abstract}
Soleus muscle fibers from the rat display a reduction in peak power and $\mathrm{Ca}^{2+}$ sensitivity after hindlimb suspension. To examine human responses to non-weight bearing, we obtained soleus biopsies from eight adult men before and immediately after 17 days of bed rest (BR). Single chemically skinned fibers were mounted between a force transducer and a servo-controlled position motor and activated with maximal (isotonic properties) and/or submaximal ( $\mathrm{Ca}^{2+}$ sensitivity) levels of free $\mathrm{Ca}^{2+}$. Gel electrophoresis indicated that all preand post-BR fibers expressed type I myosin heavy chain. Post-BR fibers obtained from one subject displayed increases in peak power and $\mathrm{Ca}^{2+}$ sensitivity. In contrast, post-BR fibers obtained from the seven remaining subjects showed an average $11 \%$ reduction in peak power $(P<0.05)$, with each individual displaying a $7-27 \%$ reduction in this variable. Post-BR fibers from these subjects were smaller in diameter and produced $21 \%$ less force at the shortening velocity associated with peak power. However, the shortening velocity at peak power output was elevated $13 \%$ in the post-BR fibers, which partially compensated for their lower force. Post-BR fibers from these same seven subjects also displayed a reduced sensitivity to free $\mathrm{Ca}^{2+}(P<0.05)$. These results indicate that the reduced functional capacity of human lower limb extensor muscles after BR may be in part caused by alterations in the cross-bridge mechanisms of contraction.
\end{abstract}

WEIGHT-BEARING ACTIVITY is recognized as an important environmental stimulus for maintaining normal neuromuscular function of the soleus and other antigravity extensor muscles. In the absence of hindlimb weight bearing, the rat soleus muscle has been shown to atrophy and to display a reduced peak tetanic tension and power output and an increased percentage of fast-twitch fibers $(3,10)$. Similar functional changes have been observed for maximally $\mathrm{Ca}^{2+}$-activated single muscle fibers isolated from the rat soleus after hindlimb suspension $(1,11,20)$. Additionally, the individual rat fibers displayed a reduced sensitivity to intracellular $\mathrm{Ca}^{2+}(1$, 11, 22). These observations suggest that at least a portion of the change in whole-muscle function after nonweight bearing can be attributed to an altered cellular function coupled with molecular changes in the type of protein expressed.

In humans, voluntary torque of the lower limb extensor muscle group is impaired after spaceflight or prolonged bed rest $(5,15)$. However, it is not clear to what extent these changes in human neuromuscular performance are due to alterations in neural mechanisms of recruitment, to changes in muscle architecture and/or fiber type composition, and/or to alterations in cellular processes of contraction.

Recently, investigators have used single-fiber in vitro preparations to study human muscle function after nonweight bearing. Larsson et al. (19) found that 42 days of complete bed rest produced large decrements in the force production of single vastus lateralis fibers along with reductions in their unloaded shortening velocity $\left(V_{0}\right)$. After 17 days of bed rest, our laboratory has observed a more modest atrophy of type I soleus fibers with an average shift in $V_{0}$ toward higher velocities (30). 
Previous human studies have concentrated on isometric and unloaded contractions $(19,30)$. These are not the conditions present during movement, when muscle fibers must shorten while under an external load. Therefore, the first goal of this study was to determine whether the isotonic contractile properties of human muscle fibers were altered after a 17-day period of bed rest. Our second goal was to characterize the force-pCa relationship (where $\mathrm{pCa}=-\log$ of the $\mathrm{Ca}^{2+}$ concentration) of human muscle fibers before and after bed rest to determine whether $\mathrm{Ca}^{2+}$ sensitivity was altered by non-weight bearing.

\section{METHODS}

This study was approved by the Institutional Review Boards at Marquette University, Ball State University, and the National Aeronautics and Space Administration (NASA) Ames Research Center. Eight men were selected from a pool of volunteers. Each subject underwent a medical examination and provided written informed consent before participation. Their mean age, height, and pre-bed-rest body mass were $43 \pm 3$ (SE) yr, $182 \pm 2$ $\mathrm{cm}$, and $82.2 \pm 4.3 \mathrm{~kg}$, respectively. Each subject was assigned an identification number of 1-8 exactly as described in our previous work (30).

Subjects resided continuously at the Human Research Facility at NASA Ames Research Center (Moffett Field, CA) during a 14-day ambulatory control period, a 17-day $6^{\circ}$ head-down-tilt bed-rest period, and an 8-day ambulatory recovery period. This duration of bed rest corresponded with the planned duration of the NASA Life and Microgravity Sciences Spacelab (LMS) space shuttle mission (shuttle transport system-78) scheduled to take place $\sim 1$ year after this study. Subjects underwent physiological evaluations during the control, bed-rest, and recovery periods as described previously (30). These evaluations were similar to that planned for the LMS mission and included determinations of maximal oxygen consumption by using a supine ergometer and evaluation of right ankle flexor torque by using a specially designed isokinetic dynamometer.

One to three days before the control period, subjects reported to the Human Research Facility, and a pre-bedrest muscle sample was obtained from the left soleus by using the percutaneous needle-biopsy technique. At the conclusion of bed rest but before reambulation, a post-bed-rest sample was obtained from the right soleus. Pre- and post-bed-rest muscle samples were divided into several portions. The portion used for the present experiments was immediately placed in cold skinning solution [composition in $\mathrm{mM}: 125 \mathrm{~K}$ propionate, 20.0 imidazole (pH 7.0), 2.0 EGTA, 4.0 ATP, and $1.0 \mathrm{MgCl}_{2}$ and $50 \%$ glycerol vol/vol] and was shipped overnight at $4^{\circ} \mathrm{C}$ to Marquette University where it was stored at $-20^{\circ} \mathrm{C}$. All contractile experiments were conducted within 28 days of muscle sampling.

The total and free concentrations of each metal, ligand, and metal-ligand complex in the relaxing and activating solutions were calculated by using an iterative computer program (6). Stability constants used in these calculations (12) were adjusted for the temperature, $\mathrm{pH}$, and ionic strength conditions of the present experiments. Each solution contained (in mM) 7 EGTA, 20 imidazole, 14.5 creatine phosphate, 1 free $\mathrm{Mg}^{2+}$, and 4 free MgATP and sufficient $\mathrm{KCl}$ and $\mathrm{KOH}$ to produce a total ionic strength of $180 \mathrm{mM}$ and a pH of 7.0. In addition, the relaxing and activating solutions had a free $\mathrm{Ca}^{2+}$ concentration of pCa 9.0 and pCa 4.5, respectively.

On the day of an experiment, a single fiber segment was isolated from the muscle bundle and transferred to a small chamber milled into a stainless steel plate. While submerged under relaxing solution, the fiber was mounted between a force transducer (Cambridge model 400, Cambridge Technology, Watertown, MA) and a direct current position motor (Cambridge model 300B, Cambridge Technology). The motor was controlled by a servomechanism similar to that described previously (18). The mounting procedure utilized 4-0 monofilament pins and 10-0 suture to fasten the fiber ends securely into small stainless steel troughs extending from the transducer and motor (31). The stainless steel plate was attached to the stage of an inverted microscope so that the fiber could be viewed at $\times 800$ during data collection. Sarcomere length was adjusted to $2.5 \mu \mathrm{m}$ by using an 
eyepiece micrometer. The length of the fiber (FL) suspended between the transducer and motor was measured with a micrometer that advanced the plate across the field of view. A Polaroid photograph was taken of the fiber while it was briefly suspended in air $(<5 \mathrm{~s})$ by using an Olympus PM-10AD photomicrographic system $(\times 300)$. Fiber diameter was determined from the average fiber width measured at three points along the photograph. The fiber diameter in micrometers was measured by using a photograph of an American Optical micrometer (10 $\mu \mathrm{m}$ per division) produced with the same photomicrographic system as the fiber photograph ( $\times 300)$. Fiber crosssectional area (CSA) was calculated from fiber diameter under the assumption that the fiber forms a circular cross section when suspended in air (23).

Vertical and horizontal displacements of the stainless steel plate enabled the mounted fiber to be rapidly transferred into an adjacent chamber filled with activating solution. Output from the force transducer and position motor were displayed on a digital oscilloscope before being amplified and interfaced to a personal computer via a LabMaster data-acquisition board. Custom software performed online analysis and stored data to disk. Relaxing and activating solutions were maintained at $15^{\circ} \mathrm{C}$ during all experiments.

The force-velocity relationship was determined from a series of isotonic releases as described in Fig. 1. $P_{\circ}$ was defined as the peak force obtained during the experiment. $V_{\max }$ was defined as the intercept of the force-velocity curve with the velocity axis. Peak absolute power was calculated from $\mathrm{P}_{\mathrm{o}}, V_{\max }$, and $a / \mathrm{P}_{\mathrm{o}}$, the parameter that specifies the curvature of the force-velocity relationship (where $a$ is a constant with dimensions of force). For graphical purposes, composite force-velocity-power relationships were plotted by using the mean parameters.
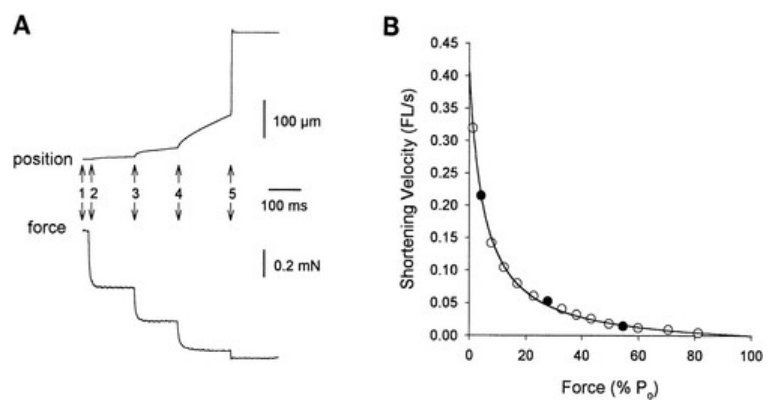

Fig. 1. Force-velocity data obtained from a representative pre-bed-rest type I soleus fiber. $A$ : force and position records for 3 consecutive isotonic steps. Fiber attained peak isometric force $\left(P_{o}\right)$ attime point 1 . At time point 2, fiber was allowed to shorten as indicated by upward deflection of position record and rapid drop in force. Betweentime points 2 and3, rate of fiber shortening was controlled by a servomechanism (18) so that fiber contracted isotonically for $150 \mathrm{~ms}$. A second and third isotonic step were applied at time points 3 and4, respectively. Attime point 5 , fiber was slackened by $20 \%$ of its original fiber length, causing force to drop to baseline. Fiber was then returned to relaxing solution and reextended to its original length. $B$ : fiber force and shortening velocity were determined over the last one-half of each isotonic step $(\bullet)$. Entire procedure was repeated so that each fiber underwent a total of 15-18 randomized isotonic loads. 0 , Data points collected during subsequent isotonic contractions; solid line, Hill equation (17) fit to data by using an iterative curve-fitting algorithm. Force-velocity parameters for this fiber were $\mathrm{P}_{\mathrm{o}}=0.95 \mathrm{mN}$, parameter that specifies the curvature of the force-velocity relationship $\left(a / P_{0}\right)=0.052$, and intercept of force-velocity curve with velocity axis $\left(V_{\max }\right) 0.41$ fiber lengths $(\mathrm{FL}) / \mathrm{s}$.

A subgroup of fibers were activated with a series of solutions that had free $\mathrm{Ca}^{2+}$ concentrations ranging from $\mathrm{pCa}$ 6.8 to pCa 5.0. These solutions were made by mixing appropriate volumes of the activating (pCa 4.5) and relaxing ( $\mathrm{pCa}$ 9.0) solutions. Peak force of each contraction was recorded and expressed as a fraction of the peak force obtained during maximal $\mathrm{Ca}^{2+}$ activation. Results for a representative fiber are plotted as in Fig.2A. The first and approximately every fourth subsequent contraction was performed at $\mathrm{pCa} 4.5$. Hill plots were used to 
determine the $\mathrm{Ca}^{2+}$ concentration associated with $\mathrm{Ca}^{2+}$ activation threshold and with half-maximal activation as described in Fig.2B.

A

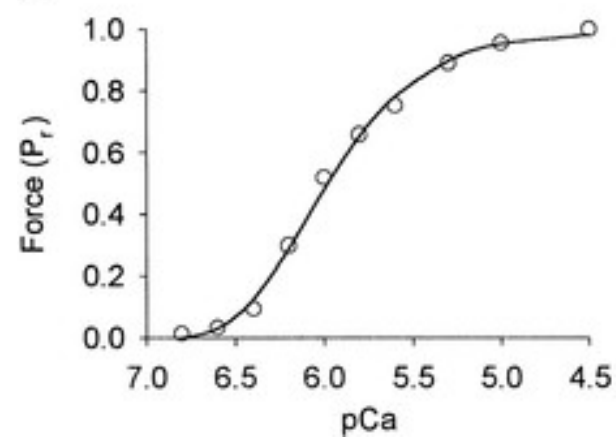

B

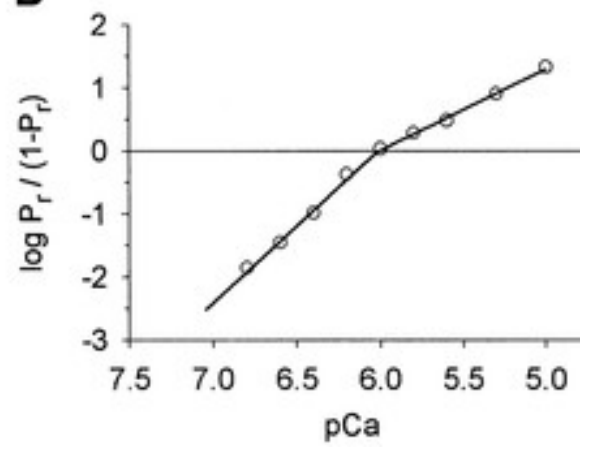

Fig. 2. Representative $\mathrm{pCa}$-force data obtained from a single pre-bed-rest type I soleus fiber (where $\mathrm{pCa}$ is $-\mathrm{log}$ of $\mathrm{Ca}^{2+}$ concentration).A: $\mathrm{pCa}$-force relationship for this fiber. Peak force for each contraction was expressed as a fraction of maximal Ca2+-activated force, i.e., submaximal force/force at pCa $4.5\left(\mathrm{P}_{\mathrm{r}}\right) . B$ : Hill plots of data illustrated inA. Least squares regression lines were fit to data points $<50 \%$ of maximal $\mathrm{Ca}^{2+}$ activated force $\left(r^{2}=0.99\right.$; slope $\left.=2.47\right)$ and data points $>50 \%$ of maximal Ca2+-activated force $\left(r^{2}=0.99\right.$; slope $\left.=1.29\right)$. Activation threshold was defined as $\mathrm{Ca}^{2+}$ concentration where $\log \mathrm{P}_{\mathrm{r}} /\left(1-\mathrm{P}_{\mathrm{r}}\right)=-2.5$. Half-maximal activation was calculated as mean intercept of least squares regression lines with the line $y=0$. In this example, activation threshold was pCa 7.04 with half-maximal activation occurring at $\mathrm{pCa} 6.02$.

After the contractile measurements, the fiber was removed from the transducer and motor, solubilized in $10 \mu \mathrm{l}$ of $1 \%$ SDS sample buffer, and stored at $-80^{\circ} \mathrm{C}$. The myosin heavy chain (MHC) content of each individual fiber was determined by $5 \%$ PAGE. A portion of each fiber was also run on a $12 \%$ gel to determine myosin light chain and thin-filament regulatory protein composition. A description of these procedures and representative 5 and $12 \%$ gels have been presented in a previous paper (30).

Fibers expressing solely type I MHC comprised $\geq 87 \%$ of the fibers randomly isolated for study from either the pre- or the post-bed-rest soleus samples (30). Consequently, these were the only fibers included in the present analysis. Pre- and post-bed-rest means were analyzed by using a two-tailed $t$-test. Statistical significance was accepted at $P<0.05$. All data are presented as means $\pm \mathrm{SE}$.

\section{RESULTS}

Isotonic contractile properties were studied on 201 pre- and 134 post-bed-rest fibers, all of which expressed type I MHC on 5\% SDS-PAGE gels. On average, the post-bed-rest type I soleus fibers were smaller in diameter (pre-bed rest: $95 \pm 1 \mu \mathrm{m}$, post-bed rest: $90 \pm 1 \mu \mathrm{m} ; P<0.05$ ), produced less peak force (pre-bed rest: $1.01 \pm 0.02$ $\mathrm{mN}$, post-bed rest: $0.89 \pm 0.02 \mathrm{mN} ; P<0.05$ ), and had a greater $V_{\max }$ (pre-bed rest: $0.52 \pm 0.02 \mathrm{FL} / \mathrm{s}$, post-bed rest: $0.71 \pm 0.05 \mathrm{FL} / \mathrm{s} ; P<0.05$ ) than did the pre-bed-rest fiber population. For the eight subjects in this study, peak power was similar before and after bed rest (pre-bed rest: $13.8 \pm 0.4 \mu \mathrm{N} \cdot \mathrm{FL} \cdot \mathrm{s}^{-1}$, post-bed rest: $13.6 \pm 0.6$ $\left.\mu \mathrm{N} \cdot \mathrm{FL} \cdot \mathrm{s}^{-1} ; P>0.05\right)$.

Figure $3 A$ demonstrates that, over the course of this study, fibers obtained from seven of the eight subjects displayed reductions in peak power. These reductions averaged $7-27 \%$ on an individual-subject basis. In contrast to the majority of subjects, the average peak power of fibers obtained fromsubject 1 increased from $12.8 \pm 1.1$ (31 fibers) to $22.5 \pm 2.1 \mu \mathrm{N} \cdot \mathrm{FL} \cdot \mathrm{s}^{-1}$ (16 fibers). This $76 \%$ relative change in peak power was over $2 \mathrm{SDs}$ greater than the average change for all eight subjects combined. 
A

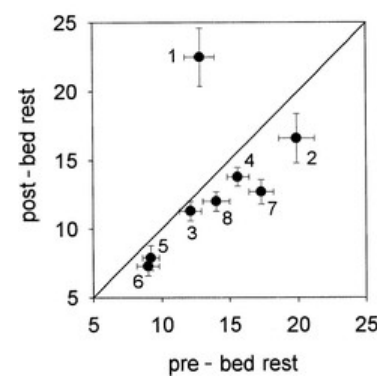

B

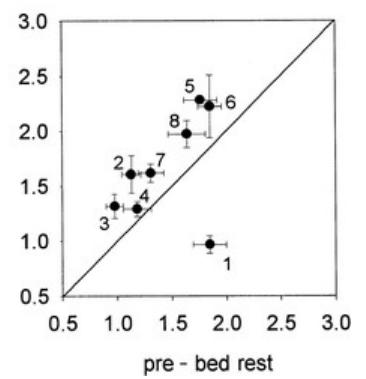

Fig. 3. Mean peak power and $\mathrm{Ca}^{2+} \mathrm{sensitivity} \mathrm{for} \mathrm{individual} \mathrm{subjects.} A$ : peak power $\left(\mu \mathrm{N} \cdot \mathrm{FL} \cdot \mathrm{s}^{-1}\right) \cdot B$ : half-maximal activation $\left(\mu \mathrm{mol} \mathrm{Ca}^{2+}\right)$. In $A$ and $B$, mean pre-bed-rest ( $x$-axis) value for each subject has been plotted vs. mean postbed-rest ( $y$-axis) value. Error bars, $\pm 1 \mathrm{SE}$. Nos. indicate subject identification nos. Solid line, line of identity. Note that subject 1 was the only subject who displayed an increase in average fiber peak power and an increase in $\mathrm{Ca}^{2+}$ sensitivity after bed rest.

Peak power rose for fibers obtained from subject 1 because their average $P_{o}$ increased by $11 \%$ and their $V_{\max }$ more than doubled. These responses differed substantially from those observed for fibers from the other seven subjects. Representative pre- and post-bed-rest fibers obtained from one of these individuals (subject 7) are illustrated in Fig.4. Comparison of the two fibers reveals that $V_{\max }$ was $50 \%$ greater $(0.42 \mathrm{vs} .0 .28 \mathrm{FL} / \mathrm{s})$, whereas $\mathrm{P}_{\mathrm{o}}$ was $35 \%$ lower $(0.81 \mathrm{vs} .1 .25 \mathrm{mN})$, for the post-bed-rest fiber. For this particular fiber, the parametera/ $\mathrm{P}_{\mathrm{o}}$ was virtually identical pre- vs. post-bed rest so that the relative force associated with peak power output was 20 and $19 \%$ of $\mathrm{P}_{\mathrm{o}}$, respectively. At $20 \%$ of $\mathrm{P}_{\mathrm{o}}$, the force and shortening velocity of the pre-bed-rest fiber were $0.250 \mathrm{mN}$ and $0.057 \mathrm{FL} / \mathrm{s}$, respectively, for a power output of $14.2 \mu \mathrm{N} \cdot \mathrm{FL} \cdot \mathrm{s}^{-1}$. At $19 \%$ of $\mathrm{P}_{\mathrm{o}}$, the force and shortening velocity of the post-bed-rest fiber were $0.155 \mathrm{mN}$ and $0.081 \mathrm{FL} / \mathrm{s}$, respectively, for a power output of $12.5 \mu \mathrm{N}$. $\mathrm{FL} \cdot \mathrm{s}^{-1}$, or $12 \%$ less than the power output observed for the pre-bed-rest fiber.

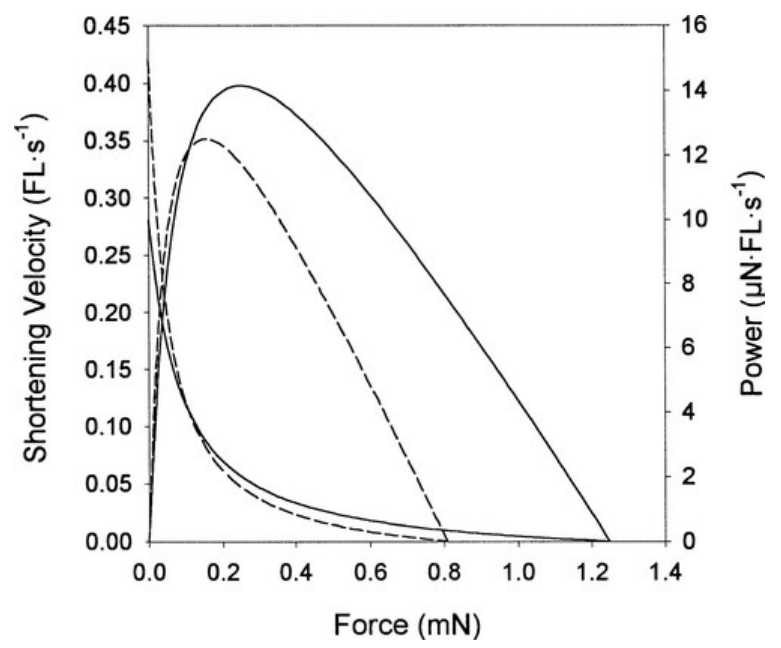

Fig. 4. Force-velocity-power relationships of a representative pre- and a post-bed-rest fiber. Both fibers were obtained fromsubject 7. Gel electrophoresis indicated that both fibers expressed type I myosin heavy chain exclusively. Solid lines, pre-bed rest; dotted lines, post-bed rest. See RESULTS for additional details

Because of the disproportionate effect that fibers fromsubject 1 had on the interpretation of our data, we performed an analysis in which fibers from this individual were eliminated. For the 170 pre- and 118 post-bedrest type I fibers obtained from subjects $2-8$, $\mathrm{P}_{\mathrm{o}}$ declined by $15 \%$ and $V_{\max }$ rose by $25 \%$ after bed rest (Table 1 ). Thea/Poratio showed a small decline from $0.051 \pm 0.002$ to $0.044 \pm 0.003$ such that the force at peak power $\left(\% \mathrm{P}_{\mathrm{o}}\right)$ significantly dropped from a pre-bed-rest value of $17.3 \pm 0.3$ to $16.3 \pm 0.3 \%$ post-bed rest $(P<0.05)$. Because of the decline in $\mathrm{P}_{\mathrm{o}}$ and the reduceda/ $\mathrm{P}_{\mathrm{o}}$ ratio, the submaximal force associated with peak power fell by 
21\% $(P<0.05 ;$ Table 1$)$. In contrast, the shortening velocity at peak power rose $(P<0.05)$ by $13 \%$ (Table 1$)$. Consequently, average peak power declined by $0.79 \times 1.13$, or by $11 \%$, with bed rest (Table 1 ). A composite force-power relationship of the pre- and post-bed-rest fibers is illustrated in Fig. 5. After bed rest, peak power was substantially reduced at virtually all absolute and relative external loads. Figure 5 shows both the observed and predicted post-bed-rest force-power relationship. The latter shows the relationship that would have occurred if fiber velocity had not increased.

Table 1. Effect of 17 days of bed rest on slow type I fiber force, shortening velocity, and power

\begin{tabular}{|l|l|l|}
\hline Variable & Pre-Bed Rest & Post-Bed Rest \\
\hline$n$ & 170 & 118 \\
\hline Peak force, $\mathrm{mN}$ & $1.04 \pm 0.03$ & $0.88 \pm 0.02^{*}$ \\
\hline Maximal shortening velocity, $\mathrm{FL} / \mathrm{s}$ & $0.50 \pm 0.02$ & $0.62 \pm 0.04^{*}$ \\
\hline Peak power, $\mu \mathrm{N} \cdot \mathrm{FL} \cdot \mathrm{s}^{-1}$ & $14.0 \pm 0.5$ & $12.4 \pm 0.5^{*}$ \\
\hline Force at peak power, $\mathrm{mN}$ & $0.182 \pm 0.006$ & $0.144 \pm 0.004^{*}$ \\
\hline Shortening velocity at peak power, $\mathrm{FL} / \mathrm{s}$ & $0.080 \pm 0.002$ & $0.090 \pm 0.004^{*}$ \\
\hline
\end{tabular}

Values are means $\pm \mathrm{SE}$ for 7 subjects (subjects $2-8$ ); $n$, no. of fibers. FL, fiber lengths.

Significant difference between pre- and post-bed-rest means, $P<0.05$.

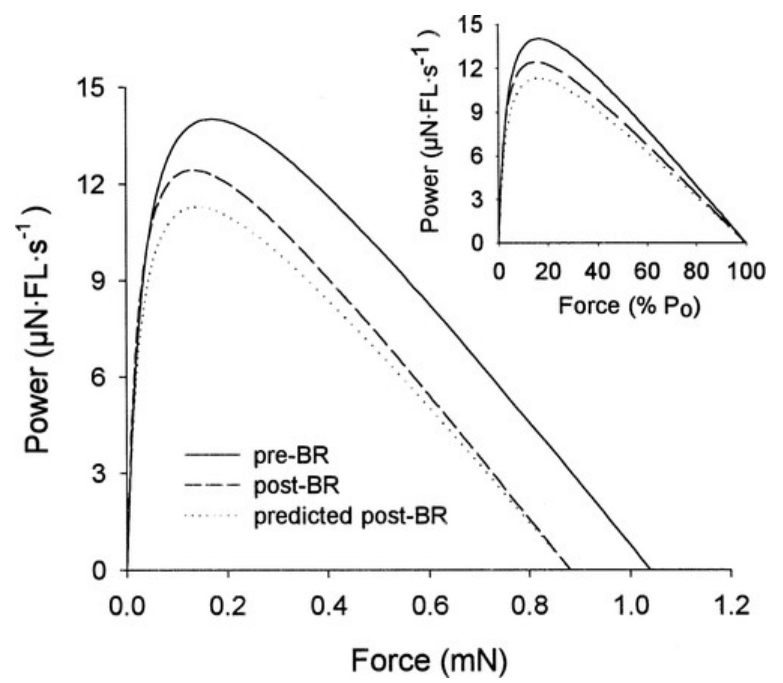

Fig. 5. Composite force-power relationships for type I soleus fibers. Curves were constructed from mean forcevelocity parameters of 7 subjects.Inset, same data plotted on a relative-force axis. Predicted curves were constructed assuming no change in fiber velocity, and a comparison of observed and predicted post-bed-rest (BR) relationships demonstrates the extent of protection induced by the increased fiber velocity.

Fiber $\mathrm{Ca}^{2+}$ sensitivity was determined from Hill-plot analysis (120 pre- and 88 post-bed-rest fibers). Again, the mean response of fibers obtained fromsubject 1 (19 pre- and 11 post-bed-rest fibers) was opposite to the responses of fibers from the other seven subjects. In Fig. $3 B$, the average $\mathrm{Ca}^{2+}$ concentrations eliciting one-half maximal activation before and after bed rest have been plotted for each subject. Subjects 2-8 displayed an average decline in $\mathrm{Ca}^{2+}$ sensitivity because substantially more free $\mathrm{Ca}^{2+}$ was required to attain half-maximal activation after bed rest. In contrast, fibers from subject 1 became more sensitive to $\mathrm{Ca}^{2+}$ over the course of this study. In a similar manner, the $\mathrm{Ca}^{2+}$ activation threshold shifted to lower and higher levels of free $\mathrm{Ca}^{2+}$ for subject 1 and subjects $2-8$, respectively (Table2). 
Table 2. Effect of 17 days of bed rest on force-pCa relationships

\begin{tabular}{|l|l|l|}
\hline Variable & Pre-Bed Rest & Post-Bed Rest \\
\hline$n$ & 101 & 77 \\
\hline Activation threshold, $\mu \mathrm{mol} \mathrm{Ca}{ }^{2+}$ & $0.078 \pm 0.003$ & $0.117 \pm 0.005^{*}$ \\
\hline Half-maximal activation, $\mu \mathrm{mol} \mathrm{Ca}{ }^{2+}$ & $1.353 \pm 0.053$ & $1.602 \pm 0.064^{*}$ \\
\hline Slope of Hill plot for $\mathrm{P}_{\mathrm{r}}<0.5\left(n_{2}\right)$ & $2.05 \pm 0.04$ & $2.27 \pm 0.05^{*}$ \\
\hline Slope of Hill plot for $\mathrm{P}_{\mathrm{r}}>0.5\left(n_{1}\right)$ & $1.40 \pm 0.03$ & $1.62 \pm 0.04^{*}$ \\
\hline
\end{tabular}

Values are means \pm SE for 7 subjects (subjects 2-8); $\mathrm{pCa}$, - $\log$ of $\mathrm{Ca}^{2+}$ concentration; $\mathrm{P}_{\mathrm{r}}$, ratio of submaximal force to maximal force as defined in Fig. 2; $n_{1}$ and $n_{2}$, slope of Hill plot for values greater than and less than halfmaximal activation, respectively.

Significant difference between pre- and post-bed-rest means, $P<0.05$.

When we eliminated subject 1 from our analysis, the average force-pCa relationship of the remaining seven subjects was shifted to the right (Fig. 6). Thus the $\mathrm{Ca}^{2+}$ required for activation threshold increased significantly with bed rest as did the $\mathrm{Ca}^{2+}$ concentration eliciting one-half maximal activation (Table 2 ). In addition, the slope of the force-pCa curve below $\left(n_{2}\right)$ and above $\left(n_{1}\right)$ half-maximal activation increased with bed rest (Table 2 ).

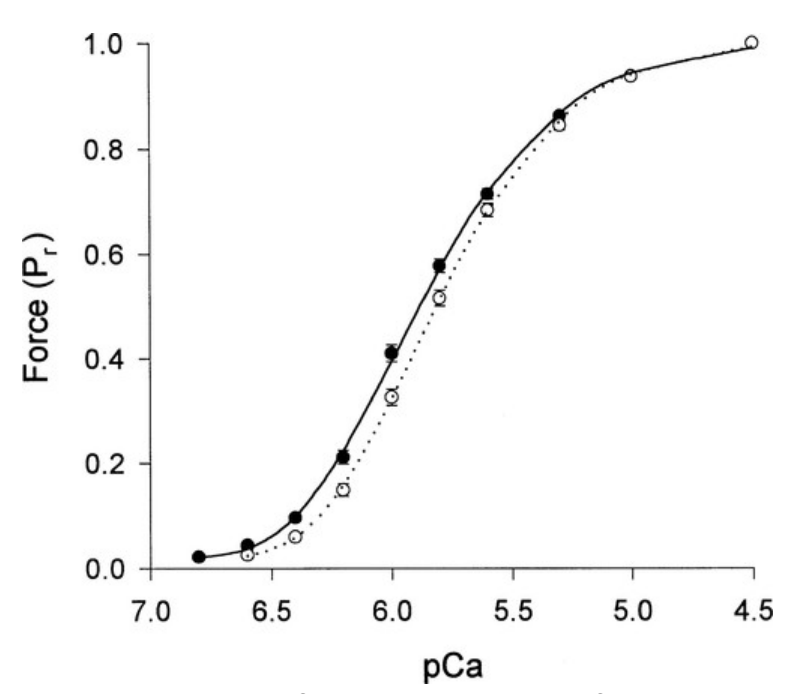

Fig. 6. Mean pCa-force relationships for type I soleus fibers. Values are means $\pm S E$ of relative force $\left(P_{r}\right)$ for 7 subjects. •, Pre-bed rest; 0 , post-bed rest.

\section{DISCUSSION}

The primary goal of this study was to investigate changes in the isotonic contractile properties of single muscle fibers after a 17-day period of non-weight bearing. We were particularly interested in peak power because this variable is an important characteristic of animal locomotor systems (26), and declines in power would likely have important physiological and functional implications both in space and on return to Earth. In this study, we focused on fibers expressing type I MHC because 1) in animal models, type I fibers are preferentially affected by non-weight bearing (11) and 2) type I fibers make up the majority of fibers present in the human soleus before and after 17 days of bed rest (28).

The average peak power of the 201 type I soleus fibers obtained before bed rest was $13.8 \pm 0.4 \mu \mathrm{N} \cdot \mathrm{FL} \cdot \mathrm{s}^{-1}$. In previous studies from this laboratory, we reported mean peak power values of $8.2 \pm 0.3$ and $9.8 \pm 0.3 \mu \mathrm{N} \cdot \mathrm{FL}$. 
$\mathrm{s}^{-1}$ for human type I gastrocnemius and type I soleus fibers, respectively $(31,32)$. The greater power values in the present study cannot be attributed to variations in shortening velocity as there was little difference in fiber $V_{\max }$ across these three studies. However, the fibers in the present study were larger in diameter and consequently produced more force than did fibers from our previous work. This appears to be the major reason for the greater peak power values in the present study. Additionally, the force-velocity relationships presented here were less curved (highera/ $\mathrm{P}_{\mathrm{o}}$ ratio), such that higher velocities were obtained at a given percent of $\mathrm{P}_{\mathrm{o}}$. Bottinelli et al. (2) studied the isotonic contractile properties of human muscle fibers, and their reported peak power value for the slow type I fiber was considerably lower than ours. The primary reason for the discrepancy was fiber force because the mean value (corrected for the different temperature employed) was $<70 \%$ of the fiber force reported here.

The average peak power for fibers obtained from seven of the eight subjects in this study declined by $11 \%$ with bed rest. A decline in peak power with non-weight bearing is consistent with observations made on type I soleus fibers obtained from adult rats subjected to hindlimb suspension $(1,20)$. However, reductions in peak power after 14-21 days of rat hindlimb suspension exceed the decline observed in the present study by a factor of three to four. Taken together, these data indicate that type I fibers from the human soleus experience less atrophy and loss of peak power than do fibers obtained from rats exposed to hindlimb suspension. This is in agreement with proposed interspecies differences in the net rate of protein loss during non-weight bearing (8).

The decline in peak power of the human fibers can be attributed primarily to a reduction in the ability of the post-bed-rest fibers to produce force, with a secondary contribution from changes in the curvature of the forcevelocity relation. The loss of force after 17 days of bed-rest results primarily from a reduction in fiber CSA coupled with a relatively small reduction in force per CSA (30). The force-velocity relationship had a slightly greater curvature after bed rest so that peak power was attained at a lower percentage of fiber $P_{0}$. Both of these changes meant that the post-bed-rest fibers produced less force when they shortened at their optimal velocity for power production. Figure 5 shows a pre-, a post-, and a predicted post-bed-rest force-power relationship. The predicted curve shows the force-power relationship that would have occurred if fiber velocity had remained unchanged and peak power had declined in direct proportion to the average $21 \%$ loss in fiber force (at peak power). It is clear from Fig. 5 that the observed reduction in peak power was only about one-half of the decline that could be explained solely by a change in force production. The reason is that when the post-bed-rest fibers were producing optimal force for power output, they were shortening at a $13 \%$ greater velocity than were the pre-bed-rest fibers. The observed peak power was therefore greater than one would predict based solely on a change in fiber force. We conclude that the elevated shortening velocity of the post-bed-rest fibers played a compensatory role by reducing the reduction in peak power that occurred during non-weight bearing.

In the present study, we included only those fibers that expressed type I MHC. In previous work, we concluded that variations in myosin light chain composition could not explain the elevated shortening velocities of postbed-rest fibers expressing type I MHC (30). The mechanism underlying the increase in their shortening velocity is therefore not clear. One possibility is that an unidentified $\mathrm{MHC}$ isoform comigrates with the adult $\beta$-MHC isoform observed on our gels (7). A second possibility pertains to morphological alterations that occur during non-weight bearing. It has recently been reported that post-bed-rest fibers obtained from the subjects in the present study had a reduction in thin filament density after the 17-day period of bed rest (25a). Shortening velocity is known to increase when the myofilament lattice spacing is expanded experimentally, whereas force changes very little under these conditions (23). Thus one would predict that power would increase as the myofilament lattice spacing increased.

It is important to note that the magnitude of the change in shortening velocity was insufficient to completely offset the lower forces of the post-bed-rest fibers. Thus countermeasures to human non-weight bearing must address the issue of muscle fiber atrophy. Also, it will be important to determine whether the increase in fiber 
shortening velocity after bed rest affects other functional properties of human muscle fibers. McDonald and Fitts (21) found that myosin ATPase activity was increased in soleus fibers from hindlimb-suspended rats. If similar changes occur in human muscle after bed rest, one might predict a decrease in the efficiency of contraction and an increase in muscle fatigability.

The plantar flexors and knee extensors produce significantly less torque at any given angular velocity after $\geq 30$ days of non-weight bearing $(5,15)$. In this study, the voluntary plantar flexor torque-velocity relationship did not change over the 17-day period of bed rest $(25,28)$. In a study of the same subjects, Narici et al. $(25)$ studied the effects of direct electrical stimulation $(50 \mathrm{~Hz})$ of the plantar flexors. They found that peak torque declined by 10 and $18 \%$ from the pre-bed-rest baseline on the 13th day of bed rest and on the 2 nd day of recovery from bed rest, respectively. These data compare favorably with our observation of a 12 (8 subjects) to $15 \%$ ( 7 subjects) reduction in peak $\mathrm{Ca}^{2+}$-activated force of single muscle fibers obtained immediately at the end of the bed-rest period. Thus, when neural mechanisms (motivation, coactivation of antagonist) modulating muscle performance were bypassed, the relative change in the strength of the triceps surae was in good agreement with the relative change in the maximal $\mathrm{Ca}^{2+}$-activated force of single soleus fibers.

Post-bed-rest fibers also experienced a significant decrease in $\mathrm{Ca}^{2+}$ sensitivity, as indicated by a $50 \%$ increase in the free- $\mathrm{Ca}^{2+}$ concentration at the activation threshold and an $18 \%$ increase in the $\mathrm{Ca}^{2+}$ required to attain halfmaximal activation. These results are qualitatively similar to those observed for rat type I soleus fibers after hindlimb suspension $(1,11,22)$. However, changes in the $\mathrm{Ca}^{2+}$ sensitivity of rat fibers are of a greater magnitude than that observed for the human fibers in the present study. Functionally, a decrease in $\mathrm{Ca}^{2+}$ sensitivity could have implications during the development of fatigue when the intracellular free- $\mathrm{Ca}^{2+}$ concentration may not completely saturate the $\mathrm{Ca}^{2+}$ binding sites of the thin filament (9). Westerblad and Allen (29) have concluded that the intracellular $\mathrm{Ca}^{2+}$ concentration of mammalian muscle fibers may drop to as low as $\mathrm{pCa} 6.0$ during fatiguing stimulation. At this intracellular $\mathrm{Ca}^{2+}$ concentration, force of the pre- and post-bed-rest fibers was 41 and $33 \%$, respectively, of the maximal force (i.e., at pCa 4.5). The greater decline in the post-bed-rest fibers can be attributed to the right shift (reduced $\mathrm{Ca}^{2+}$ sensitivity) in the force-pCa relationship (Fig. 6).

We also found that the slopes of the force-pCa relationship $\left(n_{1}\right.$ and $\left.n_{2}\right)$ increased after bed rest (Table 2). An increased $n_{1}$ and $n_{2}$ is generally interpreted as an indication of a greater degree of molecular cooperativity during activation of the cross bridge. The degree of cooperativity (indicated by the value of $n_{1}$ and $n_{2}$ ) can be influenced by alterations in thin-filament regulation such as an increased affinity of troponin $\mathrm{C}$ for $\mathrm{Ca}^{2+}$ and/or by thickfilament regulation (24).

A number of mechanisms are believed to confer $\mathrm{Ca}^{2+}$ sensitivity to skeletal muscle fibers [for recent review, see Moss et al. (24)]. In fast- and intermediate-velocity mammalian fibers, expression of the fast isoforms of troponin I, troponin $\mathrm{T}$, and/or tropomyosin is associated with a decrease in $\mathrm{Ca}^{2+}$ sensitivity and an increase in cooperative activation of the thin filament $(14,27)$. In this regard, de novo expression of the fast isoforms of troponin T and troponin I have been reported in rat soleus muscles after hindlimb suspension (4). However, it is not known what effect, if any, these isoform shifts have on the force-pCa characteristics of slow fibers. Second, analysis of the present fibers on $12 \%$ polyacrylamide gels revealed the presence of only the slow isoform of troponin $\mathrm{T}$ in pre- and post-bed-rest fibers (data not shown). We were unable to reliably quantify troponin I isoforms because, for human fibers, this protein tends to comigrate with myosin light chain ${ }_{2}$ on our gel system. An alternate hypothesis is that the rightward shift in the force-pCa relationship was a result of the same mechanism proposed for the increase in shortening velocity, i.e., a change in filament lattice geometry. A rightward shift in the force-pCa relationship occurs when the filament lattice expands by 20\% (13).

It is difficult to explain why fibers obtained fromsubject 1 showed increases in peak power and $\mathrm{Ca}^{2+}$ sensitivity with bed rest. Contractile properties of pre-bed-rest fibers obtained from this individual were within normal 
limits (for example, see Fig. 3). What is surprising is that the post-bed-rest fibers obtained from this individual were, on average, larger in diameter than his pre-bed-rest fibers. As a result, the post-bed-rest fibers produced more force and power. This cannot be attributed to a problem with compliance because subjects were monitored $24 \mathrm{~h}$ /day by the staff at the NASA Ames Research Center. It also seems unlikely that these post-bedrest results were due to methodological factors. Post-bed-rest fibers from this subject were studied at the same time, and with the same equipment and solutions, as were the post-bed-rest fibers from the other seven subjects. It is important to note that subject 1 displayed a reduction in electrically elicited plantar flexor torque that was similar to the responses of the other seven subjects (M. V. Narici, personal communication). Thus, at the whole-muscle level, subject 1 appeared no different from the other subjects. The most plausible explanation for the disparate results of this subject at the single-fiber level is that his post-bed-rest biopsy sample was simply not representative of the soleus muscle as a whole. Recently, Harridge et al. (16) proposed a similar explanation for discrepancies between contractile properties measured at the whole-muscle and single-fiber levels in human subjects.

In summary, the peak power output of type I soleus fibers obtained from seven of eight subjects declined by an average of $11 \%$ after 17 days of bed rest. This decline in peak power would have doubled if not for a bed-restinduced rise in fiber shortening velocity. Fibers from these same subjects showed a small, but statistically significant, reduction in $\mathrm{Ca}^{2+}$ sensitivity and an increase in cooperative activation of the cross bridge. These results provide a cellular basis for a number of the functional changes observed at the whole muscle level after bed rest, particularly in experimental designs where neural mechanisms regulating muscle activation are bypassed.

The authors especially thank all of the subjects for their commitment throughout the study and the staff of the Human Research Facility at the National Aeronautics and Space Administration (NASA) Ames Research Center, especially Dee O'Hara and Dr. Sara Arnaud.

\section{FOOTNOTES}

This research was supported by NASA Grant NAS9-18768 (to R. H. Fitts).

\section{AUTHOR NOTES}

Address for reprint requests: R. H. Fitts, Marquette Univ., Dept. of Biology, Wehr Life Sciences Bldg., P.O. Box 1881, Milwaukee, WI 53201-1881.

\section{REFERENCES}

1 Bangart J. J., Widrick J. J., Fitts R. H.Effect of intermittent weight bearing on soleus fiber force-velocity-power and force-pCa relationships. J. Appl. Physiol. 82199719051910

2 Bottinelli R., Canepari M., Pellegrino M. A., Reggiani C.Force-velocity properties of human skeletal muscle fibres: myosin heavy chain isoform and temperature dependence.J. Physiol. (Lond.)4951996573586

3 Caiozzo V. J., Haddad F., Baker M. J., Herrick R. E., Prietto N., Baldwin K. M.Microgravity-induced transformations of myosin isoforms and contractile properties of skeletal muscle.J. Appl. Physiol.811996123132

4 Campione M., Ausoni S., Guezennec C. Y., Schiaffino S.Myosin and troponin changes in rat soleus muscle after hindlimb suspension.J. Appl. Physiol.74199311561160

5 Dudley G. A., Duvoisin M. R., Convertino V. A., Buchanan P.Alterations of the in vivo torque-velocity relationship of human skeletal muscle following 30 days exposure to simulated microgravity.Aviat. Space Environ. Med.601989659663 
6 Fabiato A., Fabiato F.Calculator programs for computing the composition of the solutions containing multiple metals and ligands used for experiments in skinned muscle cells.J. Physiol. Paris 751979463505

7 Fauteck S. P., Kandarian S. C.Sensitive detection of myosin heavy chain composition in skeletal muscle under different loading conditions.Am. J. Physiol.268Cell Physiol. 371995C419C424

8 Ferrando A. A., Lane H. W., Stuart C. A., Davis-Street J., Wolfe R. R.Prolonged bed rest decreases skeletal muscle and whole body protein synthesis.Am. J. Physiol.270Endocrinol. Metab. 331996E627E633

9 Fitts R. H.Cellular mechanisms of muscle fatigue.Physiol. Rev.7419944994

10 Fitts R. H., Metzger J. M., Riley D. A., Unsworth B. R.Models of disuse: a comparison of hindlimb suspension and immobilization.J. Appl. Physiol.60198619471953

11 Gardetto P. R., Schluter J. M., Fitts R. H.Contractile function of single muscle fibers after hindlimb suspension.J. Appl. Physiol.66198927392749

12 Godt R. E., Lindley B. D.Influence of temperature upon contractile activation and isometric force production in mechanically skinned muscle fibers of the frog.J. Gen. Physiol.801982279297

13 Godt R. E., Maughan D. W.Influence of osmotic compression on calcium activation and tension in skinned muscle fibers of the rabbit.Pflügers Arch.3911981334337

14 Greaser M. L., Moss R. L., Reiser P. J.Variations in contractile properties of rabbit single muscle fibres in relation to troponin T isoforms and myosin light chains.J. Physiol. (Lond.)40619888598

15 Grigoryeva L. S., Kozlovskaya I. B.Effect of weightlessness and hypokinesis on velocity and strength properties of human muscles.Kosm. Biol. Aviakosm. Med.2119872730

16 Harridge S. D. R., Bottinelli R., Canepari M., Pellegrino M. A., Reggiani C., Esbjörnsson M., Saltin B.Wholemuscle and single-fibre contractile properties and myosin heavy chain isoforms in humans.Pflügers Arch.4321996913920

17 Hill A. V.The heat of shortening and the dynamic constants of muscle.Proc. R. Soc. Lond. B Biol. Sci.1261938136195

18 Julian F. J., Moss R. L.Effects of calcium and ionic strength on shortening velocity and tension development in frog skinned muscle fibres.J. Physiol. (Lond.)3111981179199

19 Larsson L., Li X., Berg W.E., Frontera W. R.Effects of removal of weight-bearing function on contractility and myosin isoform composition in single human skeletal muscle cells.Pflügers Arch.4321996320328

20 McDonald K. S., Blaser C. A., Fitts R. H.Force-velocity and power characteristics of rat soleus muscle fibers after hindlimb suspension.J. Appl. Physiol.77199416091616

21 McDonald K. S., Fitts R. H.Effect of hindlimb unweighting on single soleus fiber maximal shortening velocity and ATPase activity.J. Appl. Physiol.74199329492957

22 McDonald K. S., Fitts R. H.Effect of hindlimb unloading on rat soleus fiber force, stiffness, and calcium sensitivity.J. Appl. Physiol.79199517961802

23 Metzger J. M., Moss R. L.Shortening velocity in skinned single muscle fibers. Influence of filament lattice spacing.Biophys. J.521987127131

24 Moss R. L., Diffee G. M., Greaser M. L.Contractile properties of skeletal muscle fibers in relation to myofibrillar protein isoforms.Rev. Physiol. Biochem. Pharmacol.1261995163

25 Narici M. V., Kayser B., Barattini P., Cerretelli P.Changes in electrically evoked skeletal muscle contractions during 17-day spaceflight and bed rest.Int. J. Sports Med.181997S290S292

25a Riley D. A., Bain J. L., Thompson J. L., Fitts R. H., Widrick J. J., Trappe S. W., Trappe T. A., Costill D. L.Disproportionate loss of thin filaments in human soleus muscle after 17-day bedrest.Muscle Nerve21199812801289

26 Rome L. C., Funke R. P., Alexander R. M., Lutz G., Aldridge H., Scott F., Freadman M.Why animals have different muscle fibre types.Nature3351988824827

27 Schachat F. H., Diamond M. S., Brandt P. W.Effect of different troponin T-tropomyosin combinations on thin filament activation.J. Mol. Biol.1981987551554 
28 Trappe S. W., Trappe T. A., Costill D. L., Fittts R. H.Human calf muscle function in response to 17-days of bed rest (Abstract).Med. Sci. Sports Exerc.281996S146

29 Westerblad H., Allen D. G.Changes of myoplasmic calcium concentration during fatigue in single mouse muscle fibers.J. Gen. Physiol.981991615635

30 Widrick J. J., Romatowski J. G., Bain J. L. W., Trappe S. W., Trappe T. A., Thompson J. L., Costill D. L., Riley D. A., Fitts R. H.Effect of 17 days of bed rest on peak isometric force and unloaded shortening velocity of human soleus fibers.Am. J. Physiol.273Cell Physiol. 421997C1690C1699

31 Widrick J. J., Romatowski J. G., Karhanek M., Fitts R. H.Contractile properties of rat, rhesus monkey, and human type I fibers.Am. J. Physiol.272Regulatory Integrative Comp. Physiol. 411997R34R42

32 Widrick J. J., Trappe S. W., Costill D. L., Fitts R. H.Force-velocity and force-power properties of single muscle fibers from elite master runners and sedentary men. Am. J. Physiol. 271 Cell Physiol. 401996C676C683 